Preprint of: Davood Rahmatabadi \& Ramin Hashemi. (2017). Experimental evaluation of forming limit diagram and mechanical properties of Nano/ultra-fine grained Aluminum strips fabricated by accumulative roll bonding process. International Journal of Materials Research. DOI: 10.3139/146.111566.

\title{
Experimental evaluation of forming limit diagram and mechanical properties of Nano/ultra-fine grained Aluminum strips fabricated by accumulative roll bonding process
}

\section{Davood Rahmatabadi , Ramin Hashemi}

School of Mechanical Engineering, Iran University of Science and Technology, Tehran, Iran

*Corresponding author: E-mail: rhashemi@iust.ac.ir (R. Hashemi) Tel.: +98-21-77240540, Fax: +98-21-77240540

\begin{abstract}
In this research, for the first time, forming limit diagrams (FLDs) of ultra-fine grained $\mathrm{Al} / \mathrm{Al}$ samples produced by accumulative roll bonding (ARB) process were evaluated. The samples were successfully prepared through ARB up to the $7^{\text {th }}$ pass. Mechanical properties, tensile fracture surfaces, and crystallite size of samples were investigated. The level of the FLD and elongation at first decreased and then increased, continuously. The results of tensile testing revealed that by increasing the number of ARB passes, the tensile strength increased continuously. Microhardness of $\mathrm{Al}$ strips increased and reached a value of $51 \mathrm{VHN}$ after the seventh pass. Results of X-ray diffraction demonstrated that crystallite size decreased from $1341 \mathrm{~nm}$ for annealed condition and it reached to $175 \mathrm{~nm}$ for ARBed samples after the $7^{\text {th }}$ pass. SEM images showed that the fracture mode in the ARBed samples was a shear ductile fracture with elongated sophomoric shear dimples.
\end{abstract}

Keywords: Forming limit diagrams; Accumulative roll bonding; Mechanical properties; SEM; AA1050 
Preprint of: Davood Rahmatabadi \& Ramin Hashemi. (2017). Experimental evaluation of forming limit diagram and mechanical properties of Nano/ultra-fine grained Aluminum strips fabricated by accumulative roll bonding process. International Journal of Materials Research. DOI: 10.3139/146.111566.

\section{Introduction}

In the last decade, aluminum has attracted the interest of many researchers for various applications such as industry, automobile manufacturing, and aerospace [1_3]. On the other hand and during these years, bulk nano and ultrafine-grained (UFG) materials have attracted significant research interest since they exhibit high strength in addition to good ductility and toughness, desirable corrosion resistance, and high speed superplastic deformation [4, 5]. Various procedures can be used to produce nano and UFG materials. Top-down and bottom-up methods are the most important and main classification of manufacturing nano and UFG materials [6, 7]. The bottomup technology includes many fabrication methods. For example, vapor deposition, mechanical alloying, and rapid solidification are bottom-up procedures. The most important and usable method from top-down procedures is the severe plastic deformation (SPD) process. So far, different accepted and successful SPD methods have been introduced, such as equal channel angular pressing (ECAP) [8, 9], equal channel angular rolling (ECAR) [10, 11], high pressure torsion (HPT) [12_14], extrusion compression (CEC) [15], multi-axial forging (MAF) [16], constrained groove pressing (CGP) [17], cyclic, and accumulative roll bonding (ARB) [18]. The common feature of all SPD methods is that the dimensions of specimens before and after applying the procedure are the same and constant [6]. Accumulative roll bonding has some better features among SPD methods, for example ARB does not need expensive equipment with high power capacity, and it can be applied to different materials [6]. Also, ARB has industrial potential because of high production rate and continuous production $[4,18]$. ARB is a repeatable technology for preparing, surface treatment, and stacking and rolling sheets with similar dimensions for a various number of cycles in order to obtain desirable mechanical properties constrained by limitations such as the growth of edge cracks [19, 20]. ARB was first introduced by Saito et al. in 1998 [18]. This process can be performed on a wide range of metals. In recent years, ARB has been broadly utilized for fabrication in the form of sheets and foils, and for various materials such as pure aluminum [5, 19, 20], aluminum alloys [3, 7, 18, 21], Zr [22], Cu [23], Brass [24], Ti [25], Mg [26], and IF steel sheets [27]. Research has mainly proved that ARB can be used in the manufacturing of multilayered metals from the same or different materials [28] and composites with metal matrix [4] with desirable and improved mechanical properties and microstructure. Moreover, some 
Preprint of: Davood Rahmatabadi \& Ramin Hashemi. (2017). Experimental evaluation of forming limit diagram and mechanical properties of Nano/ultra-fine grained Aluminum strips fabricated by accumulative roll bonding process. International Journal of Materials Research. DOI: 10.3139/146.111566.

studies demonstrated that the mechanical properties, such as tensile strength and microhardness, can be increased more than two and even more than three times these of primary material before $\mathrm{ARB}$, but the elongation decreases. Most research on ARB are about the microstructure and mechanical properties, but there are no works on the forming behavior and formability of metals in this process. Obviously, due to the reduction in elongation and developments in the production by ARB, more research is needed in the field of forming and formability. The capability of sheet metals to be formed into a desired shape without necking or fracture is generally considered as sheet metal formability. It is clear that an understanding of formability in ARBed samples can be improved and may develop the potential and practical efficacy for such applications in industry.

The forming limit diagram (FLD) is the most popular criterion utilized to forecast the formability of sheet metals and the possibility of success and failure of sheet metal forming processes. FLD demonstrates the limiting surface strains that a sheet metal can withstand before the start of localized necking under a wide range of deformation modes in tensile_tensile and tensile_compressive loading paths. This plot represents the combinations of major and minor surface strains that lead to failure of the metal [29]. The right and left side of this diagram are determined by the positive and negative minor strains, respectively. Also, there are many strain paths to biaxial and uniaxial tension from plane strain [30]. The FLDs could be obtained theoretically and experimentally. The most well-known test in order to obtain FLDs experimentally is an out-of-plane test (e.g., Nakazima test) in which a sheet metal specimen is fixed between circular die rings and stretched by a hemispherical punch [31]. The laboratory test results demonstrated that the FLDs are influenced by many factors, including strain rate [32, 33], strain hardening index, anisotropy coefficients [34, 35], heat treatment [36,37], grain size and microstructure [38, 39], strain path changes [40, 41], and sheet thickness [42]. However, work has not been done so far to evaluate the FLDs of samples produced by ARB; FLD has been used to evaluate the formability of fine grained and ultra-fine grained sheet metals produced by other SPD methods, such as ECAR [43] and ECAP [44].

In this research, in order to investigate forming limits, FLDs of ultra-fine grained $\mathrm{Al}$ samples produced by ARB were evaluated. For this purpose, the ARB process was applied at ambient temperature without using lubricant in seven passes. Mechanical properties, micro-hardness, and 
Preprint of: Davood Rahmatabadi \& Ramin Hashemi. (2017). Experimental evaluation of forming limit diagram and mechanical properties of Nano/ultra-fine grained Aluminum strips fabricated by accumulative roll bonding process. International Journal of Materials Research. DOI: 10.3139/146.111566.

fracture mode were investigated for the annealed sample and after the first, third, fifth, and seventh cycle after the ARB process. Finally, the FLDs were determined experimentally using the Nakazima test.

\section{Experimental procedure}

\subsection{Research material}

Table 1 details the material used in this study: commercially pure aluminum 1050 alloy (99.44 Al, 0. $406 \mathrm{Fe}, 0.121 \mathrm{Si}, 0.033$ ) sheet with initial dimensions of $120 \mathrm{~mm}$ in length, $75 \mathrm{~mm}$ in width, and $1 \mathrm{~mm}$ in thickness. Before the ARB process, to achieve the well-structure, the samples were annealed. Annealing and cooling were done in the furnace at $380{ }^{\circ} \mathrm{C}$ for $60 \mathrm{~min}$ and in air at ambient temperature, respectively.

\subsection{Accumulative roll bonding process}

In order to evaluate the tensile fracture surfaces, mechanical properties and forming limit diagrams of multilayered $\mathrm{Al}$ produced through the ARB process, sheets were prepared into $120 \mathrm{~mm} \times 75$ $\mathrm{mm} \times 1 \mathrm{~mm}$ in length, width and thickness, respectively. Figure 1 illustrates the principle of the ARB process utilized to manufacture the multilayer Al. The surface preparation was performed in steps: degreasing by acetone, drying in air, and roughening by circular stainless steel wire brush with dimensions of $8 \mathrm{~mm}$ and $0.3 \mathrm{~mm}$ in diameter and wire thickness, respectively. After surface preparation, the two aluminum sheets were stacked on each other; to avoid sliding, the stack was fastened by steel wires at four corner points for the ARB process. Finally, the roll-bonded sheets with a $50 \%$ reduction in thickness value were created after clamping. The ARB process was repeated for seven cycles. The process was performed using a laboratory rolling mill with $107 \mathrm{~mm}$ in roller diameters at room temperature, in which no lubricant was used. Also, to diminish reformation of oxide layers on the surface, the time between surface preparations and rolling was reduced.

\subsection{Structural evaluation}

In order to evaluate qualitatively and quantitatively different ARB cycles, X-ray diffraction (XRD) measurements were carried out on the RD-TD plane of the ARB processed sheets. The XRD experiments were performed in an X-ray diffractometer (Bruker Avance D8) using $\mathrm{Cu}-\mathrm{k}_{\alpha}$ radiation $(\lambda=0.1542 \mathrm{~nm})$, operated at $40 \mathrm{kV}, 0.5$ step size and $40 \mathrm{~mA}$, and the data were collected at room 
Preprint of: Davood Rahmatabadi \& Ramin Hashemi. (2017). Experimental evaluation of forming limit diagram and mechanical properties of Nano/ultra-fine grained Aluminum strips fabricated by accumulative roll bonding process. International Journal of Materials Research. DOI: 10.3139/146.111566.

temperature with a $2 \theta$ range between $30^{\circ}$ and $80^{\circ}$. The Williamson-Hall formula and X'Pert High Score software were used to analyze the XRD data. Also, the crystallite sizes were calculated for each peak, separately, and then the average of crystallite size for each peak at different ARB passes reported.

\subsection{Mechanical properties}

Mechanical properties of Al multi-layered fabricated by the ARB process were studied through uniaxial tensile tests and microhardness measurements. The uniaxial tensile test samples were prepared for the annealed and ARBed samples oriented along the rolling direction according to the ASTM: E8 standard. The gauge length and width of the tensile test specimens were 25 and $6 \mathrm{~mm}$, respectively. The uniaxial tensile tests were performed at a nominal initial strain rate of $1.67 \times$ $10^{-4} \mathrm{~s}^{-1}$ at room temperature using a SANTAM tensile testing machine. Vickers microhardness tests were coducted on initial and ARBed samples using JENUS apparatus under a load of $200 \mathrm{~g}$ applied for $10 \mathrm{~s}$. Microhardness tests were implemented to the intial and ARBed samples at 10 different points randomly on the cross-sections perpendicular to the rolling direction. Then, for each sample, the minimum and maximum hardness values were disregarded. Also, to determine the fracture mode for annealed and ARB processed samples at different ARB passes, the fracture surfaces of the uniaxial tensile test specimens were evaluated using a VEGA TESCAN SEM.

\subsection{Forming limit diagrams}

The Nakazima test was used to determine the FLD. The Nakazima test uses the biaxial stretchforming tests to obtain FLDs [45]. Specimens with different geometries were used to obtain the forming limit curve (FLC) [46]. Rectangular samples of different widths were cut by wire cut machine from the sheet metals $50 \mathrm{~mm}$ in length, corresponding to one fourth of ISO 12004 standard dimensions and perpendicular to the rolling direction. Also, to mark the circular grid with 2.5 (0.1 inch) mm diameter and a depth of 1 micrometer over the surface of the initial and ARBed specimens, on electro-chemical procedure was used. For stretching sheet samples, a SANTAM S20 50_ton constant speed hydraulic press machine equipped with a displacement-force curve and $2 \mathrm{mmmin}^{-1}$ speed was employed. An abrupt change in the load-displacement diagram was utilized as the stopping criterion in the test. The experimental equipment and different steps for determination of FLD, such as the Nakazima test, specifying necking and fracture points, reading 
Preprint of: Davood Rahmatabadi \& Ramin Hashemi. (2017). Experimental evaluation of forming limit diagram and mechanical properties of Nano/ultra-fine grained Aluminum strips fabricated by accumulative roll bonding process. International Journal of Materials Research. DOI: 10.3139/146.111566.

the large and small diameters of deformed elliptic shapes by travelling microcopy, calculating the major and minor strain, and drawing FLD are illustrated in Fig. 2. Typical deformed samples after Nakazima test are shown in Fig. 3. The circular grids were deformed to elliptical shapes by the tests. After conducting the out-of-plane stretching test for each sample, the limited strains were determined from the major and minor axes of the ellipse, located nearest to the localized necking region, using a traveling microscope with an accuracy of $1 \mu \mathrm{m}$. The major and minor engineering strains were calculated via Eqs. (1) and (2), respectively, and were then transformed into the true strains:

$$
\begin{aligned}
e_{\text {major (\%) }} & =\frac{a-d}{d} \times 100 \\
e_{\text {minor (\%) }} & =\frac{b-d}{d} \times 100
\end{aligned}
$$

" $a$ ", " $b$ ", and " $d$ " introduce the ellipse's major and minor diameters and the initial circle diameter, respectively.

\section{Results and discussion}

\subsection{Structural evaluation}

Figure 4a depicts the typical XRD patterns of pure $\mathrm{Al}$ and $\mathrm{Al}$ with the index plane after different ARB passes. The crystallite size, as one of the important structural parameters of nano-materials, can be obtained XRD, as the crystallite size is related to the diffraction peak broadening. Significant peak broadening is observed especially for the smallest crystallite size values. It can be seen that by increasing the applied strain, not much change is seen in peak location, and also by increasing the number of ARB cycles, the peak broad increased.

Figure $4 \mathrm{~b}$ illustrates the variation in crystallite size after various ARB passes and unprocessed aluminum. The crystallite size decreased from $1341 \mathrm{~nm}$ for pure $\mathrm{Al}$ to about $175 \mathrm{~nm}$ at the seventh pass. In general, the microstructure variation is based on the separation of grains. Regarding the ultra-fine grained ARBed samples, in the ARB process due to high applied strain with increasing number of ARB passes, the boundaries of different geometries are arranged in parallel bundles, and according to the axis of the deformation [47]. By increasing the stress and strain, the number 
Preprint of: Davood Rahmatabadi \& Ramin Hashemi. (2017). Experimental evaluation of forming limit diagram and mechanical properties of Nano/ultra-fine grained Aluminum strips fabricated by accumulative roll bonding process. International Journal of Materials Research. DOI: 10.3139/146.111566.

of minor borders and the boundaries of different geometries increase, and the distance between them decreases, and finally the mechanism leads to grain refinement [47].

\subsection{Fractography}

Tensile fracture surfaces after uniaxial tensile testing were viewed using the SEM for evaluation of the fracture mode. Tensile fracture surfaces of primary strips and the multilayer $\mathrm{Al}$ as a function of the ARB passes are presented in Figs 5 and 6, respectively. According to Fig. 5 for the initial strips, the common ductile fracture mechanism was seen accompanied by deep equiaxed or hemispheroidal dimples in the rupture surfaces of the initial annealed sheet. This type of rupture happens through micro-void formation, coalescence, crack growth, and shear fracture at an angle relative to the tensile direction $[48,49]$.

According to Fig. 6, by increasing the number of ARB passes, lamellar structure diminished after the last pass (the seventh pass). Also, by increasing the number of ARB passes, the dimples got smaller and shallower compared to the annealed sample. The appearance of these dimples in the rupture surfaces of the ARBed samples (Fig. 6) suggests the occurrence of the common shear ductile fracture mechanism similar to the initial sample, but the dimples get smaller and shallower, causing increased tensile strength and decreased elongation compared to the initial sample [48, 50]. The failure surfaces of the initial (Fig. 5) and ARBed samples (Fig. 6) show some hemispheroidal and small dimples, and that some dimples are distributed in one or other direction because of applying unequal triaxial stresses. These dimples are features of a typical ductile fracture. Each dimple is attributed to a crack nucleation site, which is linked up during the plastic deformation process [51]. Briefly, for initial strips, the ductile fracture was accompanied by deep and equiaxed dimples and for aluminum_aluminum ARBed sheet, a shear ductile fracture was observed. Moreover, dimple sizes of Al ARBed samples are smaller and shallower than the dimples of initial strips. Viewing the lower magnification of Fig. 6, debonding between layers is determined by red arrows at the first and last ARB passes. By increasing the number of ARB passes and applied strain, debonding decreased and resulted in better and stronger bonding between Al layers. 
Preprint of: Davood Rahmatabadi \& Ramin Hashemi. (2017). Experimental evaluation of forming limit diagram and mechanical properties of Nano/ultra-fine grained Aluminum strips fabricated by accumulative roll bonding process. International Journal of Materials Research. DOI: 10.3139/146.111566.

\subsection{Mechanical properties}

The initial annealed material (AA1050) had the lowest yield tensile strength and very large elongation about $34 \%$, and tensile strength of nearly $55 \mathrm{MPa}$ was obtained. The engineering stress-strain curves of the multilayer $\mathrm{Al}$ as a function of the number of $\mathrm{ARB}$ cycles are presented in Fig. 7a. According to Fig. 7a, ultimate tensile and (0.2\%) yield strength were quickly enhanced after the first pass of the ARB process, and then with rising the number of ARB passes to the seventh pass, it slowly increased. The strain hardening rate of the soft phase and flow properties of the constituent phases affected the mechanical properties of the metallic multilayer, especially tensile properties [52]. Two basic mechanisms are responsible for strengthening during the ARB process, strain hardening by dislocations and grain refinement [20, 52, 53]. Increasing the strength in the initial passes (at least before 3 ) of the ARB process is attributed to strain hardening and cold work [53, 54]. After initial passes (after the third pass) and by decreasing the effect of work hardening, strengthening and higher strengths are achieved through the gradual evolution of the microstructure $[25,54,55]$. With increasing the number of ARB passes, crystallite size and separation between layers decreased, and the bond strength between aluminum layers increased, leading to the increased strength. The maximum yield and tensile strength $198 \mathrm{MPa}$ and 231.7 MPa were achieved at the seventh pass, respectively.

The values of ultimate tensile, $(0.2 \%)$ yield strength, and elongation obtained from the engineering stress-strain curves (Fig. 7a) for the Al ARBed sheets at different number of passes, and the initial samples are presented in Fig. 7b. According to Fig. 7b, the elongation of phases indicates a sharp decrease in the first ARB cycle, and then elongation is improved by continuing the ARB process. Based on previous research studies, the low elongation value in the ARBed samples can be attributed to the high strain hardening and debonding between Al layers. After the first cycle and by increasing the number of ARB passes, higher elongation is achieved by grain refinement, and the gradual evolution of ultra-fine grains plays the main role in enhancing the elongation.

Elongation of multilayered $\mathrm{Al}$ after the first cycle of the ARB was $3.44 \%$ and improved as the ARB process continued and reached $7.82 \%$ after the seventh pass (the last pass). From the third to the seventh pass, both values of elongation and tensile strength increased, continuously, due to grained refinement and because the grained refinement is the only mechanism that enhances 
Preprint of: Davood Rahmatabadi \& Ramin Hashemi. (2017). Experimental evaluation of forming limit diagram and mechanical properties of Nano/ultra-fine grained Aluminum strips fabricated by accumulative roll bonding process. International Journal of Materials Research. DOI: 10.3139/146.111566.

strength and ductility at the same time. It is reported in similar research (similar in primary material, reduction in thickness, temperature, process, and applied strain) that the grain sizes of the $1^{\text {st }}, 3^{\text {rd }}$, and $5^{\text {th }}$-cycle of ARB processed AA1050 sheets measured from TEM micrographs were approximately $465 \mathrm{~nm}, 406 \mathrm{~nm}$, and $300 \mathrm{~nm}$, respectively [56].

During the ARB process, the samples are assumed to be deformed in a plane strain condition. Therefore, the equivalent strain after $n$ cycles can be determined using the following Eq [18]:

$$
\varepsilon_{\text {eq }}=\frac{2}{\sqrt{3}} N \ln \frac{t_{0}}{t}=\frac{2}{\sqrt{3}} N \ln \frac{1}{1-R}
$$

Where $t_{0}, t, N$, and $R$ are the initial thickness, thickness of samples after ARB process, number of ARB cycles, and reduction thickness in each pass, respectively.

As shown in Table 2, by raising the number of ARB passes, the microhardness of $\mathrm{Al}$ increased. The micro hardness of phases indicated a sharp rise in the first ARB pass from 25 to 45 VHN. After the first pass, there was a moderate increase in the microhardness, and finally it became approximately constant in the last pass (the seventh) of the ARB process and reached 51.5 VHN after the seventh pass. The increase rate of microhardness in the initial passes of the ARB is attributed to the high rate of strain hardening [52,57], and in the next passes both strain hardening and grain refinement are effective on the microhardness increase; in the last ARB pass, the microhardness reaches an approximately constant value because the materials arrive a steady-state density of dislocations. Annihilation in the dynamic recovery process and dynamic balance between dislocation generation during plastic deformation creates steady-state density of dislocations $[52,54]$.

\subsection{Forming limit diagram}

Figure 8 demonstrates forming limit diagram for the annealed sample and $\mathrm{Al}$ at different passes of the accumulative roll bonding process. According to Fig. 8, formability (FLD and FLD 0 ) decreased sharply in the first ARB pass and then improved and increased continuously after the first pass with rising number of ARB passes gradually. Declining of the FLDs was chiefly due to strain hardening which decreases the movement of dislocations. Also, decreased the formability and ductility in Fig. 8 can be due to debonding in the interfaces [7]. Enhancing the FLDs by increasing the ARB cycles could be due to the diminution effect of strain hardening, grain refinement, and 
Preprint of: Davood Rahmatabadi \& Ramin Hashemi. (2017). Experimental evaluation of forming limit diagram and mechanical properties of Nano/ultra-fine grained Aluminum strips fabricated by accumulative roll bonding process. International Journal of Materials Research. DOI: 10.3139/146.111566.

other reasons such as creation of stronger bonds and decreasing separation between $\mathrm{Al}$ layers [7]. According to Fig. 4b, by increasing the number of ARB passes, the grain size decreased and grain refinement increased. Also, by applying equivalent strain over 0.8 (after first cycle), the values of grain size were below $500 \mathrm{~nm}[56,58]$. After transition of the third pass to the seventh pass, both values of strength and formability increased at the same time; the main reason is dominance of the grain refinement mechanism. Also, previous studies show that after the third pass, the effect of cold working decreases, and the grain refinement is the governing mechanism $[25,54,55,59,60]$. In summary, decreased formability of initial ARB cycles is due to strain hardening, debonding, and weak bonding in the interfaces. On the other hand, increased formability after higher ARB cycles (at least after 3 cycles) is due to the diminution effect of strain hardening and grain refinement. The $F L D_{0}$ of multilayered $\mathrm{Al}$ after the first pass of the ARB was five and enhanced as the ARB process continued and reached 14.5 after the seventh pass. The $F L D_{0}$ and elongation obtained from the engineering stress-strain curves (Fig. 7a) and forming limit diagrams (Figure 8) of the $\mathrm{Al}$ sheets are illustrated in Table 2, as a function of the accumulative roll bonding passes. According to Table 2, the elongation and $F L D_{0}$ values dramatically decreased from $34 \%$ and 23 $\%$ to $3.5 \%$ and $5 \%$ after one pass of ARB process, respectively. Then, the elongation and $F L D_{0}$ values were enhanced by increasing the number of ARB passes and reached the maximum after the seventh cycle to $7.8 \%$ and $14.5 \%$ and decreased to $77 \%$ and $37 \%$, respectively, compared to the annealed samples. The reduced rate of elongation was more than $F L D_{0}$ and also improved 122 $\%$ and $190 \%$, compared to the first cycle. The improved rate of $F L D_{0}$ was more than elongation.

\section{Conclusion}

In the present study, multilayer aluminum was fabricated by the ARB process, and the mechanical properties, the microstructures, and the FLDs of ARBed samples after different number of passes of the ARB process were evaluated; the following results can be summarized:

I. The yield and tensile strengths were quickly enhanced after the initial pass of the ARB process, and then with increasing the number of $\mathrm{ARB}$ cycles to the seventh cycle, it slowly increased, and the maximum yield and tensile strength reached $198 \mathrm{MPa}$ and $231.7 \mathrm{MPa}$ respectively after the seventh pass. 
Preprint of: Davood Rahmatabadi \& Ramin Hashemi. (2017). Experimental evaluation of forming limit diagram and mechanical properties of Nano/ultra-fine grained Aluminum strips fabricated by accumulative roll bonding process. International Journal of Materials Research. DOI: 10.3139/146.111566.

II. The elongation and $F L D_{0}$ values dramatically decreased from $34 \%$ and $23 \%$ to $3.5 \%$ and $5 \%$ after the first ARB pass, registering $90 \%$ and $78 \%$ decreases, respectively. Then, the elongation and $F L D_{0}$ values were enhanced by increasing the number of ARB passes and reached a maximum after the seventh cycle to $7.8 \%$ and $14.5 \%$, which demonstrated an improvement compared to the first cycle of $122 \%$ and $190 \%$, respectively; the improved rate of $F L D_{0}$ was more than the elongation.

III. Microhardness measurement demonstrated that the sharp rising in the first pass and value of microhardness increased from 25 to 45 VHN. Then, there was a moderate increase, and finally, the microhardness reached an approximately constant value.

IV. The crystallite sizes, as one of the important structural parameters of nano-materials, were obtained by X-ray diffraction. By increasing the number of ARB passes, crystallite size decreased from $1341 \mathrm{~nm}$ for the annealed samples to $175 \mathrm{~nm}$ for the last ARB pass.

V. The SEM observations showed that ductile fracture with large dimples occurred in the annealed specimen, changing to shear ductile fracture with elongated sophomoric shear and fine dimples after the ARB process. Also, by increasing the number of ARB passes, the debonding between layers decreased.

VI. From the third to seventh pass, the ductility (elongation and FLD) and strength increased continuously at the same time; due to the dominance of grain refinement. Also, decrease in the formability of the first ARB passes occurred due to strain hardening, cold work, and high separation between Al layers at the first pass. 
Preprint of: Davood Rahmatabadi \& Ramin Hashemi. (2017). Experimental evaluation of forming limit diagram and mechanical properties of Nano/ultra-fine grained Aluminum strips fabricated by accumulative roll bonding process. International Journal of Materials Research. DOI: 10.3139/146.111566.

\section{References:}

[1] J. Evancho, J. Kaufman: SAE Technical Paper. 1977. DOI: 10.4271/770307

[2] L. Troeger, E. Starke: Mater. Sci. Eng. A 277 (2000) 102. DOI: 10.1016/S09215093(99)00543-2

[3] S. Lee, Y. Saito, T. Sakai, H. Utsunomiya: Mater. Sci. Eng. A 325 (2002) 228. DOI: 10.1016/S0921-5093(01)01416-2

[4] R. Jamaati, M.R. Toroghinejad: Mater. Des. 31 (2010) $4816 . \quad$ DOI: 10.1016/j.matdes.2010.04.048

[5] M. Raei, M.R. Toroghinejad, R. Jamaati: Mater. Manuf. Pro. 26 (2011) 1352. DOI: 10.1080/10426914.2011.557133

[6] H. Pirgazi, A. Akbarzadeh, R. Petrov, L. Kestens: Mater. Sci. Eng. A 497 (2008) 132. DOI: 10.1016/j.msea.2008.06.025

[7] M.R. Toroghinejad, F. Ashrafizadeh, R. Jamaati: Mater. Sci. Eng. A 561 (2013) 145. DOI: 10.1016/j.msea.2012.11.010

[8] R.Z. Valiev, T.G. Langdon: Prog. Mater. Sci. 51 (2006) 881. DOI: 10.1016/j.pmatsci.2006.02.003

[9] R.Z. Valiev, N. Krasilnikov, N. Tsenev: Mater. Sci. Eng. A 137 (1991) 35. DOI: 10.1016/09215093(91)90316-F

[10] V. Segal: Mater. Sci. Eng. A 197 (1995) 157. DOI: 10.1016/0921-5093(95)09705-8

[11] M. Furukawa, Y. Iwahashi, Z. Horita, M. Nemoto, T.G. Langdon: Mater. Sci. Eng. A 257 (1998) 328. DOI: 10.1016/S0921-5093(98)00750-3

[12] G. Sakai, Z. Horita, T.G. Langdon: Mater. Sci. Eng. A 393 (2005) 344. DOI: 10.1016/j.msea.2004.11.007

[13] A.P. Zhilyaev, T.G. Langdon: Prog. Mater. Sci. 53 (2008) 893. DOI: 10.1016/j.pmatsci.2008.03.002

[14] Z. Horita, D.J. Smith, M. Furukawa, M. Nemoto, R.Z. Valiev, T.G. Langdon: J. Mater. Res. 11 (1996) 1880. DOI: 10.1557/JMR.1996.0239

[15] M. Richert, H. Stüwe, J. Richert, R. Pippan, C. Motz: Mater. Sci. Eng. A. 301 (2001) 237. DOI: $10.1016 / \mathrm{S} 0921-5093(00) 01803-7$

[16] J. Yin, J. Lu, H. Ma, P. Zhang: J. Mater. Sci. 39 (2004) 2851. DOI: 10.1023/B:JMSC.0000021463.83899.b3

[17] D.H. Shin, J.-J. Park, Y.-S. Kim, K.-T. Park: Mater. Sci. Eng. A 328 (2002) 98. DOI: 10.1016/S0921-5093(01)01665-3

[18] Y. Saito, H. Utsunomiya, N. Tsuji, T. Sakai: Acta. Mater. 47 (1999) 579. DOI: 10.1016/S1359-6454(98)00365-6

[19] N. Tsuji, Y. Saito, S.H. Lee, Y. Minamino: Adv. Eng. Mater. 5 (2003) 338. DOI: 10.1002/adem.200310077

[20] X. Huang, N. Tsuji, N. Hansen, Y. Minamino: Mater. Sci. Eng. A 340 (2003) 265. DOI: 10.1016/S0921-5093(02)00182-X

[21] M.R. Rezaei, M.R. Toroghinejad, F. Ashrafizadeh: Mater. Sci. Eng. A 529 (2011) 442. DOI: 10.1016/j.msea.2011.09.057

[22] P. Hsieh, Y. Hung, J. Huang: Scr. Mater. 49 (2003) 173. DOI: 10.1016/S13596462(03)00207-0 
Preprint of: Davood Rahmatabadi \& Ramin Hashemi. (2017). Experimental evaluation of forming limit diagram and mechanical properties of Nano/ultra-fine grained Aluminum strips fabricated by accumulative roll bonding process. International Journal of Materials Research. DOI: 10.3139/146.111566.

[23] M. Shaarbaf, M.R. Toroghinejad: Mater. Sci. Eng. A 473 (2008) 28. DOI: 10.1016/j.msea.2007.03.065

[24] S. Pasebani, M.R. Toroghinejad: Mater. Sci. Eng. A 527 (2010) 491. DOI: 10.1016/j.msea.2009.09.029

[25] D. Terada, S. Inoue, N. Tsuji: J. Mater. Sci. 42 (2007) 1673. DOI: 10.1007/s10853-006-09097

[26] M. Zhan, Y. Li, W. Chen, W. Chen: J. Mater. Sci. 42 (2007) 9256. DOI: 10.1007/s10853$007-1885-2$

[27] N. Tsuji, R. Ueji, Y. Minamino: Scr. Mater. 47 (2002) 69. DOI: 10.1016/S13596462(02)00088-X

[28] D. Yang, P. Cizek, P. Hodgson, C.e. Wen: Scr. Mater. 62 (2010) 321. DOI: 10.1016/j.scriptamat.2009.11.036

[29] S.P. Keeler: SAE Technical Paper. 1965. DOI: 10.4271/650535

[30] R. Hashemi, H. Mamusi, A. Masoumi: Proceedings of the Institution of Mechanical Engineers, Part B: J. Eng. Manuf. (2014) 0954405414522448. DOI: 10.1177/0954405414522448

[31] C. Zhang, L. Leotoing, D. Guines, E. Ragneau: J. Mater. Pro. Technol. 209 (2009) 3849. DOI: 10.1016/j.jmatprotec.2008.09.003

[32] C. Zhang, X. Chu, D. Guines, L. Leotoing, J. Ding, G. Zhao: Mater. Des. 67 (2015) 522. DOI: 10.1016/j.matdes.2014.10.074

[33] A. Rezaee-Bazzaz, H. Noori, R. Mahmudi: Int. J. Mech. Sci. 53 (2011) 262. DOI: 10.1016/j.ijmecsci.2011.01.007

[34] F. Zhang, J. Chen, J. Chen, X. Zhu: Int. J. Mech. Sci. 89 (2014) 40. DOI: 10.1016/j.ijmecsci.2014.08.016

[35] K. Wang, J.E. Carsley, L. Zhang, T.B. Stoughton, J. Li, B.E. Carlson: Int. J. Mech. Sci. 82 (2014) 13. DOI: 10.1016/j.ijmecsci.2014.02.025

[36] N.B.K. Babu, M. Davidson, A.N. Rao, K. Balasubramanian, M. Govindaraju: Mater. Design. 55 (2014) 35. DOI: 10.1016/j.matdes.2013.10.004

[37] W. Lee, X. Wen: Int. J. Mech. Sci. 48 (2006) 134. DOI: 10.1016/j.ijmecsci.2005.08.005

[38] E. Karajibani, R. Hashemi, M. Sedighi: Int. J. Adv. Manuf. Technol. 90 (2017) 2713. DOI: 10.1007/s00170-016-9585-1

[39] M. Nurcheshmeh, D.E. Green: Int. J. Mech. Sci. 53 (2011) 145. DOI: 10.1016/j.ijmecsci.2010.12.004

[40] A. Assempour, R. Hashemi, K. Abrinia, M. Ganjiani, E. Masoumi: Comput. Mater. Sci. 45 (2009) 195. DOI: 10.1016/j.commatsci.2008.09.025

[41] O. Yigit: Int. J. Adv. Manuf. Technol. 67 (2013) 2689. DOI: 10.1007/s00170-012-4684-0

[42] K. Ito, K. Satoh, M. Goya, T. Yoshida: Int. J. Mech. Sci. 42 (2000) 2233. DOI: 10.1016/S0020-7403(00)00004-7

[43] H. Rahimi, M. Sedighi, R. Hashemi: Part L: J. Mater. Des. Appl. (2016). DOI: $10.1177 / 1464420716655560$

[44] R. Lapovok, I. Timokhina, P. McKenzie, R. O'Donnell: J. Mater. Pro. Technol. 200 (2008)

441. DOI: $10.1016 /$ j.jmatprotec.2007.08.083

[45] R. Hashemi, G. Faraji, K. Abrinia, A.F. Dizaji: Int. J. Adv. Manuf. Technol. 46 (2010) 551. DOI: $10.1007 / \mathrm{s} 00170-009-2121-9$

[46] F. Ozturk, D. Lee: Journal of Materials Processing Technology. J. Mater. Pro. Technol. 170 (2005) 247. DOI: 10.1016/j.jmatprotec.2005.05.010 
Preprint of: Davood Rahmatabadi \& Ramin Hashemi. (2017). Experimental evaluation of forming limit diagram and mechanical properties of Nano/ultra-fine grained Aluminum strips fabricated by accumulative roll bonding process. International Journal of Materials Research. DOI: 10.3139/146.111566.

[47] D. Hughes, N. Hansen: Acta. Mater. 45 (1997) 3871. DOI: 10.1016/S1359-6454(97)00027$\mathrm{X}$

[48] M. Naseri, A. Hassani, M. Tajally: Cer. Int. 41 (2015) 3952. DOI: 10.1016/j.ceramint.2014.11.079

[49] L. Ceschini, G. Minak, A. Morri: Comp. Sci. Technol. 66 (2006) 333. DOI: 10.1016/j.compscitech.2005.04.044

[50] A. Shabani, M.R. Toroghinejad, A. Shafyei: Mater. Sci. Eng. A 558 (2012) 386. DOI: 10.1016/j.msea.2012.08.017

[51] M. Reihanian, F.K. Hadadian, M. Paydar: Mater. Sci. Eng. A 607 (2014) 188. DOI: 10.1016/j.msea.2014.04.013

[52] M. Alizadeh, M. Samiei: Mater. Des. 56 (2014) 680. DOI: 10.1016/j.matdes.2013.11.067

[53] N. Hansen, X. Huang, R. Ueji, N. Tsuji: Mater. Sci. Eng. A 387 (2004) 191. DOI: 10.1016/j.msea.2004.02.078

[54] Y. Wang, E. Ma: Acta. Mater. 52 (2004) 1699. DOI: 10.1016/j.actamat.2003.12.022

[55] N. Tsuji, Y. Ito, Y. Saito, Y. Minamino: Scr. Mater. 47 (2002) 893. DOI: 10.1016/S13596462(02)00282-8

[56] L. Su, C. Lu, H. Li, G. Deng, K. Tieu: Mater. Sci. Eng. A 614 (2014) 148. DOI: 10.1016/j.msea.2014.07.032

[57] M. Alizadeh, M. Paydar, F.S. Jazi: Comp. Part B: Eng. 44 (2013) 339. DOI: 10.1016/j.compositesb.2012.04.069

[58] S.O. Gashti, A. Fattah-alhosseini, Y. Mazaheri, M.K. Keshavarz: J. Alloy. Compound. 688, Part B (2016) 44. DOI: 10.1016/j.jallcom.2016.07.177

[59] M. Sedighi, M.H. Vini, P. Farhadipour: Powder. Metal. Cer. 55 (2016) 413. DOI: 10.1007/s11106-016-9821-0

[60] M.H. Vini, M. Sedighi, M. Mondali: Int. J. Mater. Res. 108 (2017) 53. DOI: $10.3139 / 146.111450$ 
Preprint of: Davood Rahmatabadi \& Ramin Hashemi. (2017). Experimental evaluation of forming limit diagram and mechanical properties of Nano/ultra-fine grained Aluminum strips fabricated by accumulative roll bonding process. International Journal of Materials Research. DOI: 10.3139/146.111566.

\section{List of figure and table captions.}

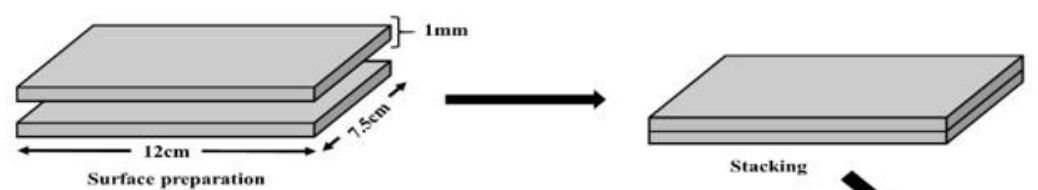

Surface preparation

Stacking

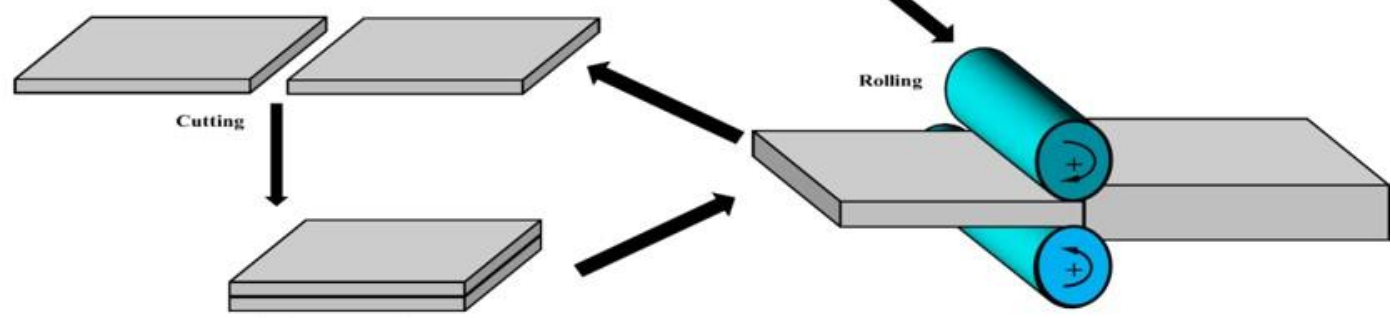

Surface preparation

Degreasing by acetone

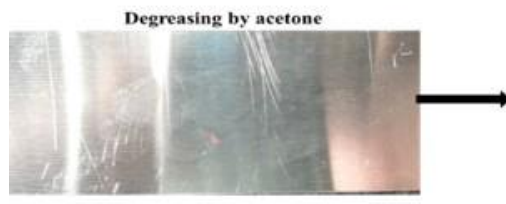

Surface preparation and piercing

Stack and fastening by steel wire
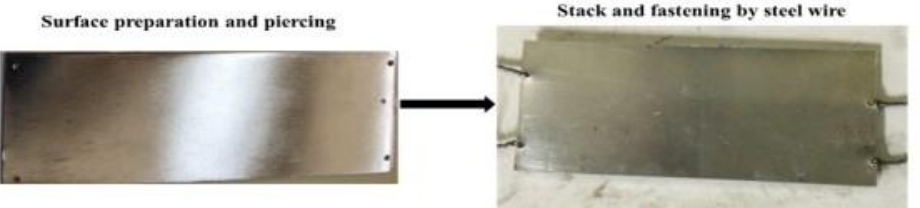

Figure 1: Schematic illustration of ARB for processing multilayered Al 
Preprint of: Davood Rahmatabadi \& Ramin Hashemi. (2017). Experimental evaluation of forming limit diagram and mechanical properties of Nano/ultra-fine grained Aluminum strips fabricated by accumulative roll bonding process. International Journal of Materials Research. DOI: 10.3139/146.111566.
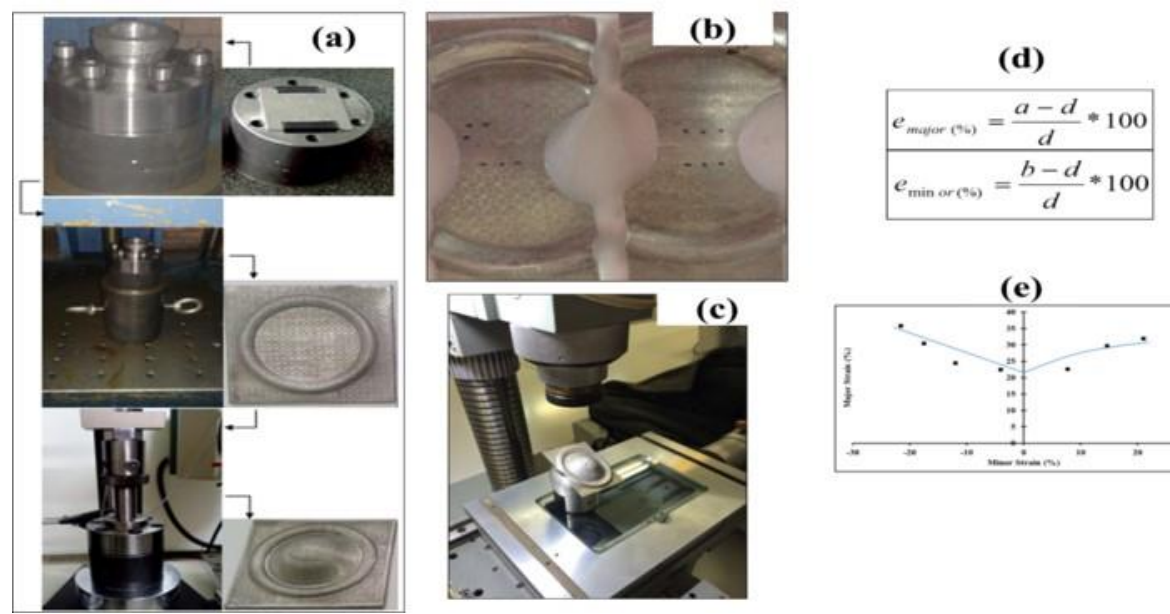

(e)

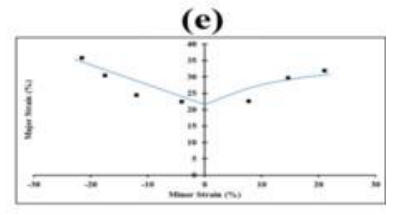

Figure 2: Different experimental FLD steps: (a) Nakazima test; (b) specifying necking and fracture points; (c) reading the large and small diameters of deformed elliptic shapes by travelling microcopy; (d) calculating the major and minor strains; (e) drawing FLD 
Preprint of: Davood Rahmatabadi \& Ramin Hashemi. (2017). Experimental evaluation of forming limit diagram and mechanical properties of Nano/ultra-fine grained Aluminum strips fabricated by accumulative roll bonding process. International Journal of Materials Research. DOI: 10.3139/146.111566.

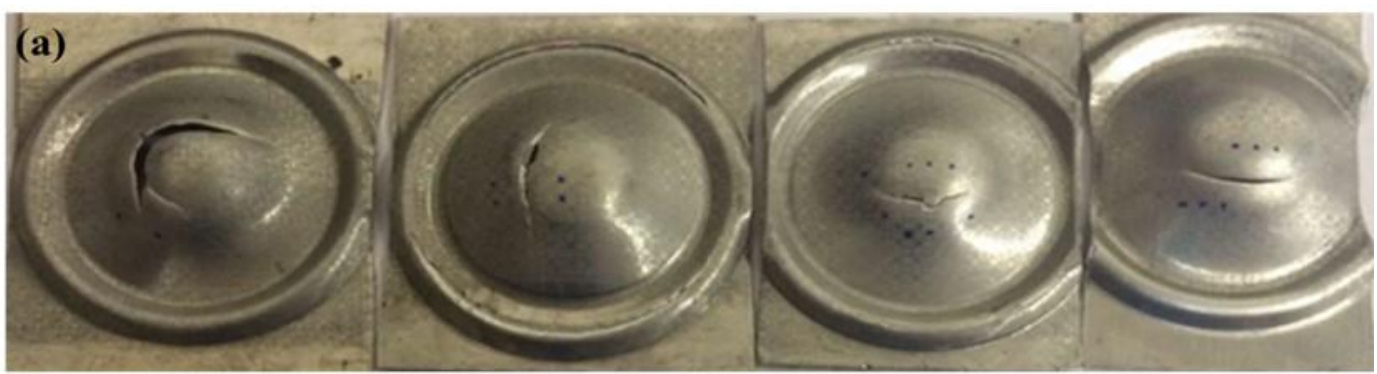

(b)

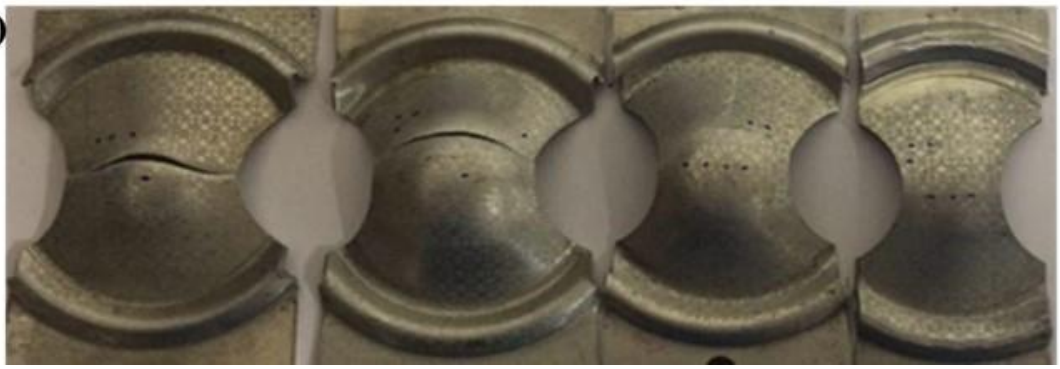

Figure 3: Typical deformed specimens for: (a) right side of FLD, and (b) left side of FLD 
Preprint of: Davood Rahmatabadi \& Ramin Hashemi. (2017). Experimental evaluation of forming limit diagram and mechanical properties of Nano/ultra-fine grained Aluminum strips fabricated by accumulative roll bonding process. International Journal of Materials Research. DOI: 10.3139/146.111566.

(a)

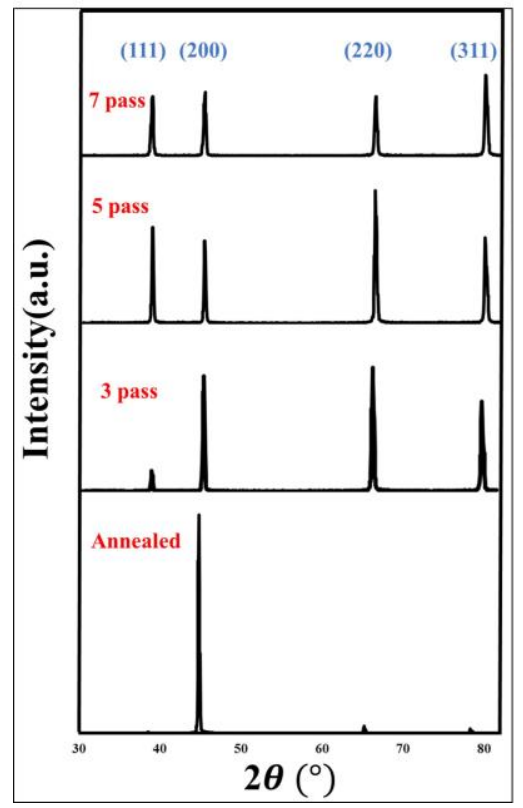

(b)

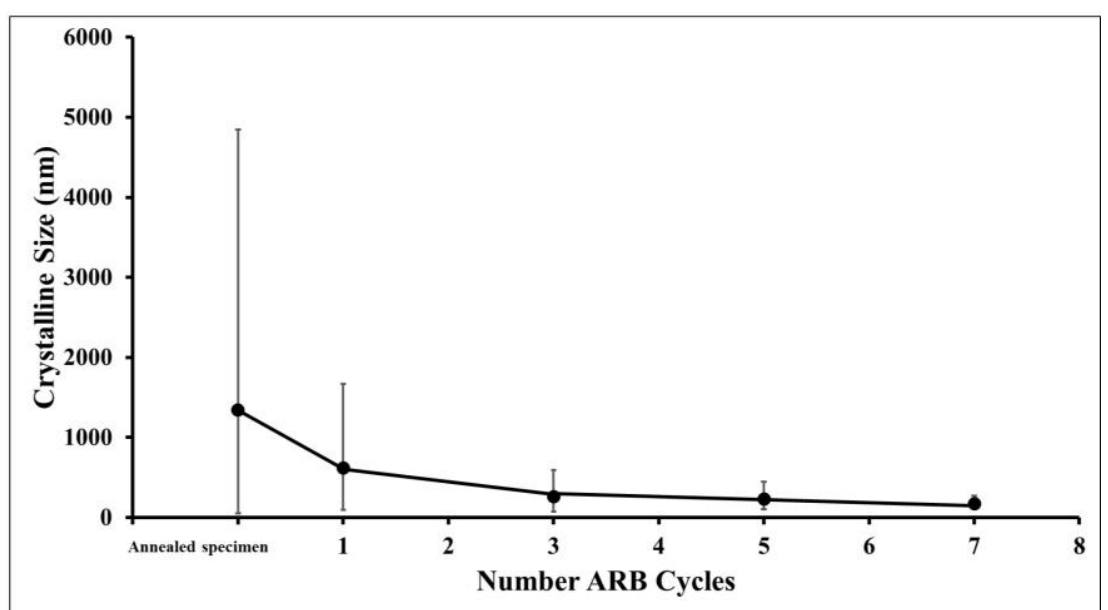

Figure 4: Results of X-ray diffraction: (a) XRD pattern of the annealed $\mathrm{Al}$ and $\mathrm{Al}$ specimens in different ARB passes, and (b) Variation of crystallite size for annealed and Al specimens in different ARB passes 
Preprint of: Davood Rahmatabadi \& Ramin Hashemi. (2017). Experimental evaluation of forming limit diagram and mechanical properties of Nano/ultra-fine grained Aluminum strips fabricated by accumulative roll bonding process. International Journal of Materials Research. DOI: 10.3139/146.111566.

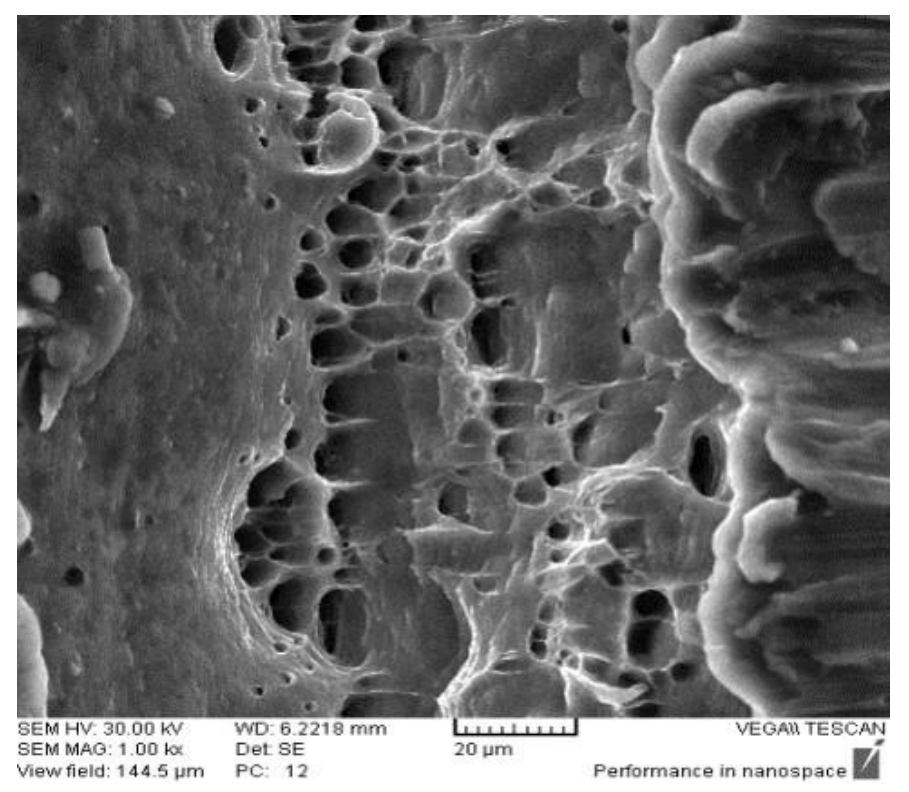

Figure 5: Tensile fracture surfaces of initial sample 
Preprint of: Davood Rahmatabadi \& Ramin Hashemi. (2017). Experimental evaluation of forming limit diagram and mechanical properties of Nano/ultra-fine grained Aluminum strips fabricated by accumulative roll bonding process. International Journal of Materials Research. DOI: 10.3139/146.111566.

(a)
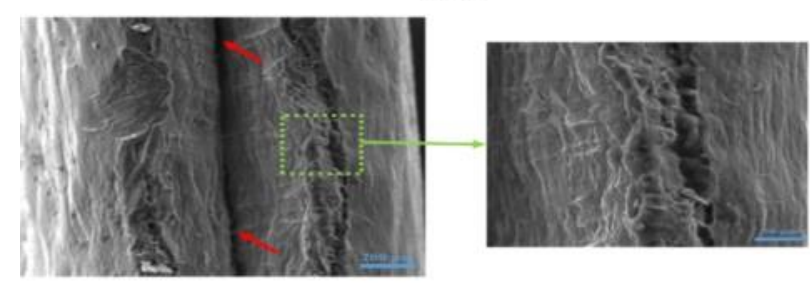

(c)

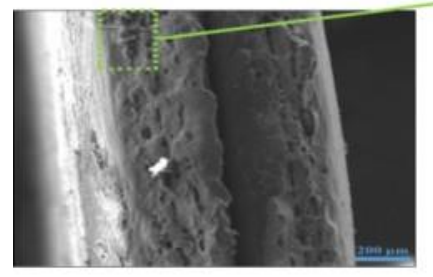

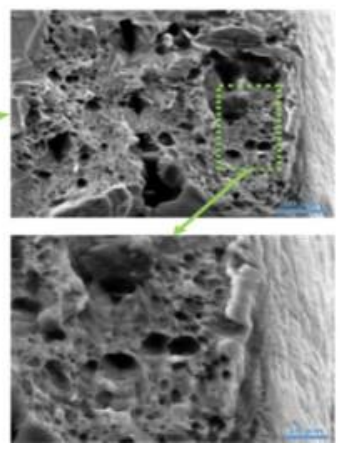

(b)
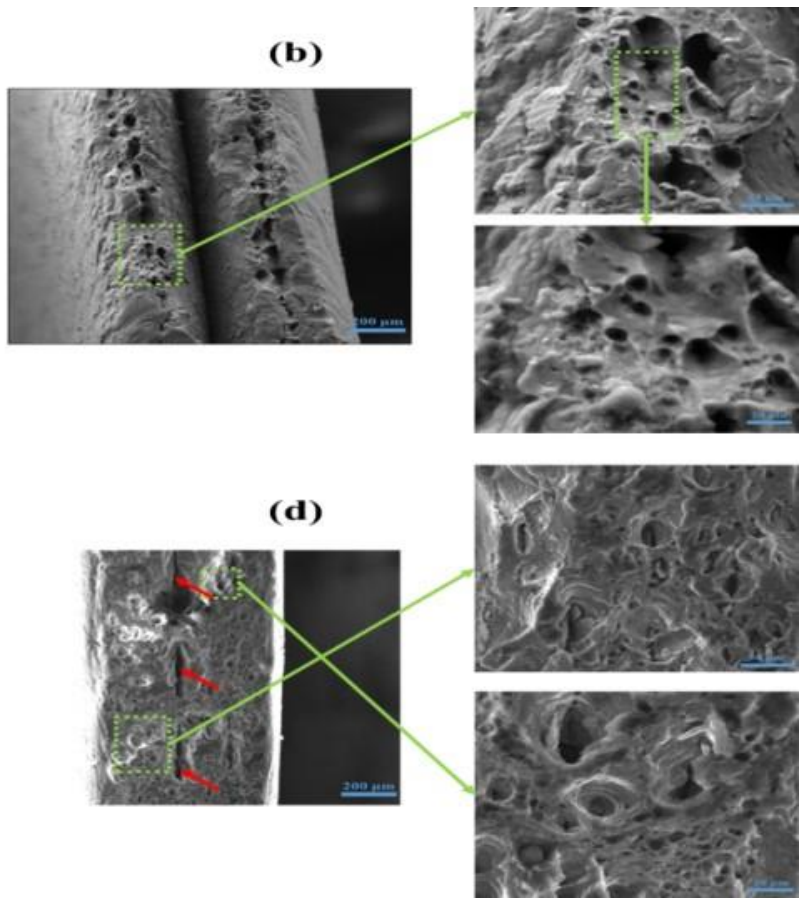

Figure 6: Tensile fracture surfaces of Al multi-layered: (a) first pass, (b) third pass, (c) fifth pass, (d) seventh pass; the red arrow shows the debonding between the layers. 
Preprint of: Davood Rahmatabadi \& Ramin Hashemi. (2017). Experimental evaluation of forming limit diagram and mechanical properties of Nano/ultra-fine grained Aluminum strips fabricated by accumulative roll bonding process. International Journal of Materials Research. DOI: 10.3139/146.111566.
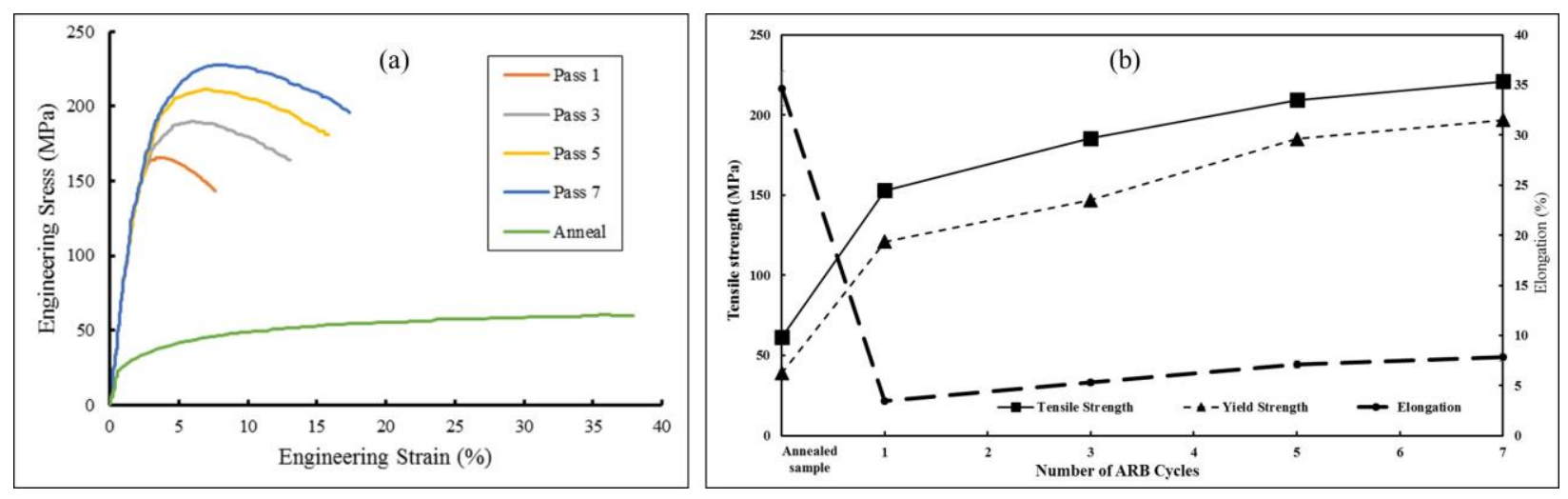

Figure 7: Mechanical properties: (a) Engineering stress-strain curves of initial sample and Al multi-layered strips in different ARB cycles and (b) Variations of tensile, yield strength, and elongation for initial sample and Al multi-layered strips after different number of ARB cycles 
Preprint of: Davood Rahmatabadi \& Ramin Hashemi. (2017). Experimental evaluation of forming limit diagram and mechanical properties of Nano/ultra-fine grained Aluminum strips fabricated by accumulative roll bonding process. International Journal of Materials Research. DOI: 10.3139/146.111566.

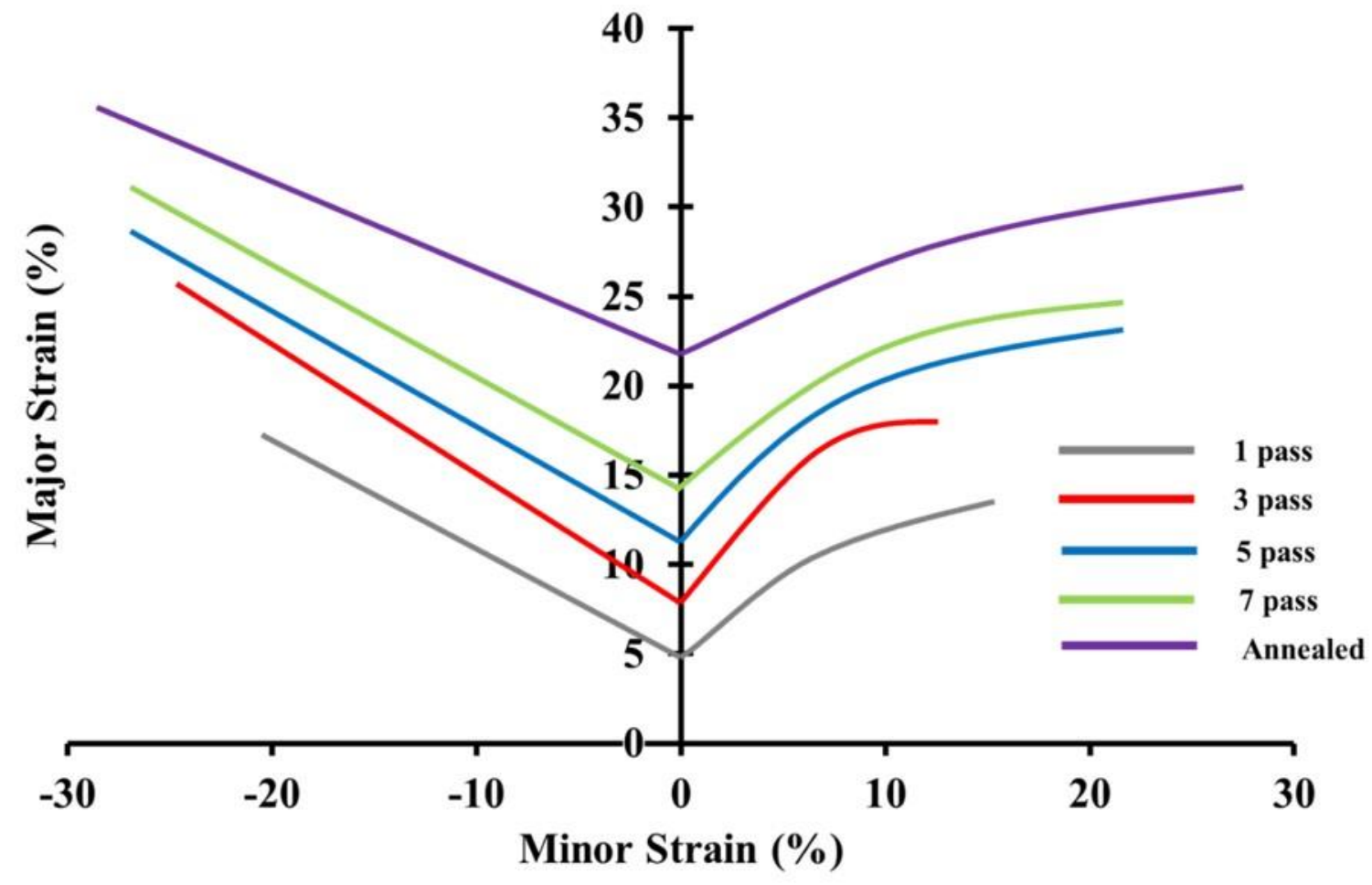

Figure 8: FLD for the initial sample and Al multi-layered strips after different number of ARB cycles 
Preprint of: Davood Rahmatabadi \& Ramin Hashemi. (2017). Experimental evaluation of forming limit diagram and mechanical properties of Nano/ultra-fine grained Aluminum strips fabricated by accumulative roll bonding process. International Journal of Materials Research. DOI: 10.3139/146.111566.

Table 1: Specifications of commercially pure aluminum.

\begin{tabular}{cccccc}
\hline Material & $\begin{array}{c}\text { Chemical } \\
\text { Composition } \\
(\text { wt.\%) }\end{array}$ & $\begin{array}{c}\text { Yield } \\
\text { Strength } \\
(\mathrm{MPa})\end{array}$ & $\begin{array}{c}\text { Tensile } \\
\text { Strength } \\
(\mathrm{MPa})\end{array}$ & $\begin{array}{c}\text { Elongation } \\
(\%)\end{array}$ & $\begin{array}{c}\text { Hardness } \\
(\mathrm{HVN})\end{array}$ \\
\hline Al & $\begin{array}{c}99.44 \mathrm{Al}, \\
0.406 \mathrm{Fe},\end{array}$ & 39 & 61 & 35 & 25 \\
1050_Anealed & $\begin{array}{c}0.121 \mathrm{Si}, \\
0.033\end{array}$ & & & & \\
\end{tabular}

Table 2: Variation of mechanical properties, $\mathrm{FLD}_{0}$, and crystallite size for annealed sample and different ARB cycles.

\begin{tabular}{ccccccc}
\hline $\begin{array}{c}\text { Number of } \\
\text { ARB } \\
\text { cycles }\end{array}$ & UTS (MPa) & $Y S(\mathrm{MPa})$ & $\begin{array}{c}\text { Elongation } \\
(\%)\end{array}$ & $F L D_{0}(\%)$ & $\begin{array}{c}\text { Micro-hardness } \\
(\text { VHN) }\end{array}$ & $\begin{array}{c}\text { Crystallite size } \\
(\mathrm{nm})\end{array}$ \\
\hline Anneal & 61.3 & 39 & 34.66 & 23 & 25 & 1341 \\
1 & 153 & 121 & 3.44 & 5 & 45 & 621 \\
3 & 185.5 & 147 & 5.3 & 8 & 48 & 264 \\
5 & 209.1 & 187 & 7.1 & 13 & 49.7 & 131 \\
7 & 231 & 198 & 7.8 & 14.5 & 51.5 & 175 \\
\hline
\end{tabular}

